\title{
EFEITOS DA CATAÇÃO ELETRÔNICA PELA COR E DO TRATAMENTO FUNGICIDA SOBRE A QUALIDADE DE SEMENTES DE FEIJÃO (Dhaseolus vulgaris L.)
}

\author{
PAULO ROBERTO DE ALBUQUERQUE LIMA \\ Engenheiro-dgrônomo
}

Orientador: Silvio Moure Cicero

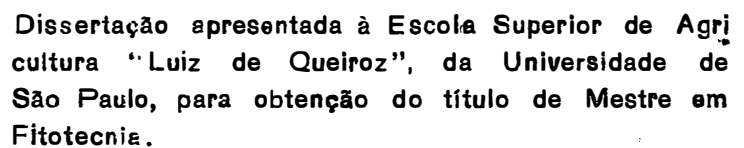

Fitotecni६.

\author{
$P \mid R A C I C A B A$ \\ Estado de São Paulo - Brasil \\ Moio, 1980
}


ii.

A memória do meu irmão

Sérgio Rubens de Albuquerque Lima,

Aos meus pais e irmãos

peros incentivos,

$D E D I C O$. 
AGRADECI MENTOS

Ao Professor Dr. Silvio Moure Cicero, pela orientàção na condução deste trabalho;

Ao Professor Dr. Julio Marcos Filho, pelas críticas e sugestões apresentadas;

Ao Professor Dr. Humberto de Campos, pelo planejamento da anālise estatística;

Ao Instituto Agronômico de Campinas, pela doação das sementes de feijão e, em particular, ao pesquisador Luiz D'Artagnan de Almeida;

A Coordenação de Aperfeiçoamento do Pessoal de Nível Superior (CAPES), pela concessão da bolsa;

Ao Engo-Agrọ Rui Seiji Yamaoka, pela colaboração na anālise estatística;

Ao pesquisador Josē Otāvio Machado Menten, do Centro de Energia Nuclear na Agricultura (CENA), pelas anālises patológicas das sementes;

Âs acadêmicas Ana Maria Aguiar dos Santos e Yourika, pelos auxílios na instalação e condução dos experimentos;

Aos funcionários do Departamento de Agricultura e Hor ticultura da E.S.A. "Luiz de Queiroz";

A Escola Superior de Agricultura "Luiz de Queíroz", pela oportunidade e facilidades concedidas para a realização desse Curso. 
Pāg.

1. RESUMO $\ldots \ldots \ldots \ldots \ldots \ldots \ldots \ldots \ldots \ldots \ldots \ldots \ldots \ldots \ldots \ldots \ldots \ldots$

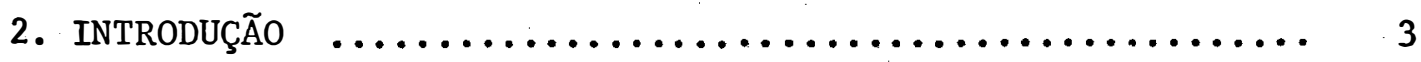

3. REVISÃo DE LiTERATURA ....................... 5

4. MATERIAIS E METODOS $\ldots \ldots \ldots \ldots \ldots \ldots \ldots \ldots \ldots \ldots \ldots \ldots \ldots \ldots$

4.1 - Sementes $\ldots \ldots \ldots \ldots \ldots \ldots \ldots \ldots \ldots \ldots \ldots \ldots \ldots \ldots \ldots \ldots \ldots$

4.2 - Preparo das Sementes $\ldots \ldots \ldots \ldots \ldots \ldots \ldots \ldots \ldots \ldots \ldots \ldots$

4.3 - Selecionadora Eletrônica $\ldots \ldots \ldots \ldots \ldots \ldots \ldots \ldots \ldots . \ldots . \ldots 12$

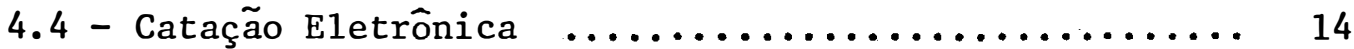

4.5 - Ambiente de Conservação $\ldots \ldots \ldots \ldots \ldots \ldots \ldots \ldots \ldots . \ldots \ldots$

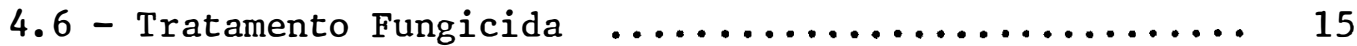

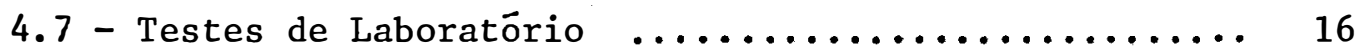

4.7 .1 - Testes de germinação ................ 16

4.7 .2 - Testes de vigor $\ldots \ldots \ldots \ldots \ldots \ldots \ldots \ldots \ldots \ldots \ldots$

4.7 .3 - Outras determinações $\ldots \ldots \ldots \ldots \ldots \ldots \ldots \ldots$

4.8 - Ensaio de Campo $\ldots \ldots \ldots \ldots \ldots \ldots \ldots \ldots \ldots \ldots \ldots \ldots \ldots$

4.8 .1 - Porcentagem de emergência de plântulas .... 18

4.8 .2 - Sobrevivência $\ldots \ldots \ldots \ldots \ldots \ldots \ldots \ldots \ldots \ldots \ldots$

4.9 - Métodos Estatísticos ....................... 19

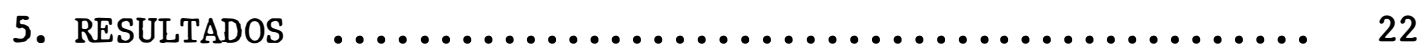

5.1 = Testes de Laboratório $\ldots \ldots \ldots \ldots \ldots \ldots \ldots \ldots \ldots \ldots \ldots . \ldots 2$

5.1 .1 - Germinação $\ldots \ldots \ldots \ldots \ldots \ldots \ldots \ldots \ldots \ldots \ldots . \ldots \ldots$ 
Pāg.

5.1 .2 - Primeira contagem de germinação $\ldots \ldots \ldots . .23$

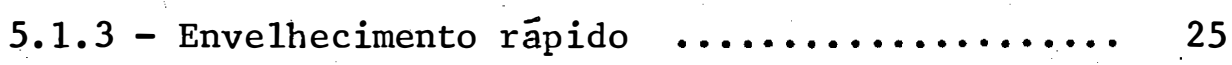

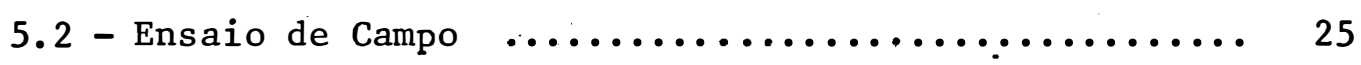

5.2 .1 - Porcentagem de emergência de plântulas ... 25

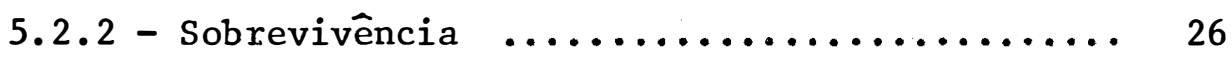

5.3 - Outras Determinações $\ldots \ldots \ldots \ldots \ldots \ldots \ldots \ldots \ldots \ldots \ldots$

5.3.1 - Sementes sem manchas $\ldots \ldots \ldots \ldots \ldots \ldots \ldots \ldots . \ldots \ldots$

5.3.2 - Sementes com mancha de levedura ....... 27

5.3 .3 - Sementes com outras manchas $\ldots \ldots \ldots \ldots \ldots 28$

5.3 .4 - Sementes enrugadas $\ldots \ldots \ldots \ldots \ldots \ldots \ldots \ldots . \ldots 28$

5.3 .5 - Sementes carunchadas ................... 29

5.3 .6 - Sementes com microorganismos $\ldots \ldots \ldots . \ldots 29$

6. DISCUSSÃo $\ldots \ldots \ldots \ldots \ldots \ldots \ldots \ldots \ldots \ldots \ldots \ldots \ldots \ldots \ldots \ldots$

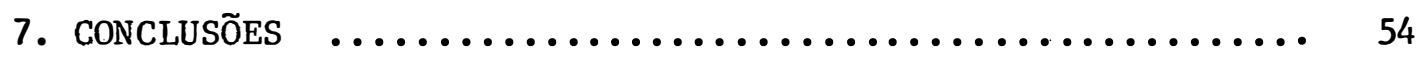

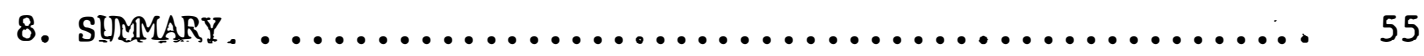

9. LITERATURA CITAdA $\ldots \ldots \ldots \ldots \ldots \ldots \ldots \ldots \ldots \ldots \ldots \ldots \ldots$ 
vi.

LISTA DE QUADROS

Pāg.

QUADRO 1 - Esquema utilizado para a anālise de variância dos dados obtidos para os testes de germinação, primei ra contagem de germinação e envelhecimento rápido.

QUADRO 2 - Esquema utilizado para a análise de variância dos dados obtidos nas sementes sem manchas, sementes com mancha de levedura, sementes carunchadas, sementes enrugadas e sementes com microorganismos ..

QUADRO 3 - Esquema utilizado para a análise de variância dos dados obtidos para os testes de porcentagem de emergência de plântulas e sobrevivência ........

QUADRO 4 - Valores de F e coeficientes de variação obtidos nos testes de germinação, primeira contagem de germina

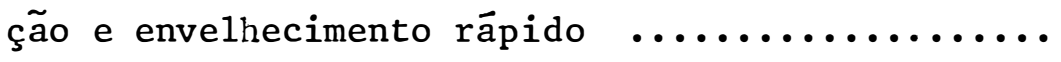

QUADRO 5 - Teste de Germinação: médias obtidas para o efeito do beneficiamento (dados transformados em arc sen $\sqrt{\mathrm{P} / 100}$ ) e a diferença mínima significativa (d.m.s.) ao nível de $5 \%$ de probabilidade ............. 31

QÚADRO 6 - Teste de Germinação: médias obtidas para o efeito da interação beneficiamento dentro de tratamento fungicida (dados transformados em arc sen $\sqrt{\mathrm{P}} / \mathbf{1 0 0}$ ) e a diferença mínima significativa (d.m.s.) ao níve1 de $5 \%$ de probabilidade $\ldots \ldots \ldots \ldots \ldots \ldots \ldots$ 
QUADRO 7 - Primeira Contagem de Germinação: médias obtidas pa ra o efeito do beneficiamento (dados transformados em arc sen $\sqrt{\mathrm{P} / 100)}$ e a diferença mínima significativa (d.m.s.) ao nível de $5 \%$ de probabilidade ...

QUADRO 8 - Primeira Contagem de Germinação: médias obtidas pạ ra o efeito do tratamento fungicida (dados transformados em arc sen $\sqrt{\mathrm{P} / 100}) \quad \ldots \ldots \ldots \ldots \ldots \ldots \ldots$

QUADRO 9 - Primeira Contagem de Germinação: médias obtidas pạ ra o efeito da interação tratamento fungicida dentro de beneficiamento (dados transformados em arc sen $\sqrt{\mathrm{P}} 7 \overline{100}$ ) e a diferença mínima significativa (d. m.s.) ao nível de $5 \%$ de probabilidade .........

QUADRO 10 - Primeira Contagem de Germinação: médias obtidas pa ra o efeito da interação do beneficiamento dentro de tratamento fungicida (dados transformados em arc sen $\sqrt{\mathrm{P} 7 \overline{100}}$ ) e a diferença mínima significativa (d.

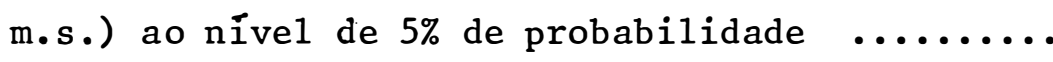

QUADRO 11 - Envelhecimento Rápido: médias obtidas para o efeito do beneficiamento (dados transformados em arc sen $\sqrt{\mathrm{P} 7 \overline{100}}$ ) e a diferença mínima significativa (d. m.s.) ao nível de $5 \%$ de probabilidade .........

QUADRO 12 - Valores de F e coeficientes de variação (\%) obtidos para: porcentagem de emergência de plântulas e sobrevivência $\quad . \ldots \ldots \ldots \ldots \ldots \ldots \ldots \ldots \ldots \ldots \ldots . \ldots \ldots$ 
viii.

Pāg.

QUADRO 13 - Porcentagem de Emergência de Plântulas: médias ob. tidas para o efeito do beneficiamento (dados trans formados em arc sen $\sqrt{\mathrm{P} 7 \overline{100}}$ ) e a diferença mínima significativa (d.m.s.) ao nível de $5 \%$ de probabili dade..$\ldots \ldots \ldots \ldots \ldots \ldots \ldots \ldots \ldots \ldots \ldots \ldots \ldots \ldots$

QUADRO 14 - Sobrevivência: médias obtidas para o efeito do be neficiamento (dados transformados em arc sen $\sqrt{\mathrm{P} 7 \overline{100}}$ e a diferença mínima significativa (d.m.s.) ao nível de $5 \%$ de probabilidade $\ldots \ldots \ldots \ldots \ldots \ldots \ldots \ldots . . \ldots$

QUADRO 15 - Sobrevivência: médias obtidas para o efeito do tratamento fungicida (dados transformados em arc sen $\sqrt{\mathrm{P} 7 \overline{100}} \quad \ldots \ldots \ldots \ldots \ldots \ldots \ldots \ldots \ldots \ldots \ldots \ldots \ldots \ldots \ldots \ldots \ldots . \ldots \ldots$

QUADRO 16 - Valores de F e coeficientes de variação (\%) obtidos para sementes sem manchas, sementes com mancha de levedura, sementes com outras manchas, sementes enrugadas, sementes carunchadas, e sementes com mi croorganismos

QUADRO 17 - Sementes sem Manchas: médias obtidas para o efeito do beneficiamento (dados transformados em arc sen $\sqrt{8} 7 \overline{100}$ ) e a diferença mínima significativa (d. m.s.) ao níve1 de $5 \%$ de probabilidade ..........

QUADRO 18 - Semente com mancha de levedura: médias obtidas pa ra o efeito do beneficiamento (dados transformados em arc sen $\sqrt{\mathrm{P} 7 \overline{100}}$ ) e a diferença mínima significativa (d.m.s.) ao nível de $5 \%$ de probabilidade .... 44 
Pāg.

QUADRO 19 - Sementes com outras manchas: médias obtidas para o efeito do beneficiamento (dados transformados em arc sen $\sqrt{\mathrm{P}} 7 \overline{100}$ ) e a diferença mínima significativa (d.m.s.) ao nível de $5 \%$ de probabilidade .......

QUADRO 20 - Sementes Enrugadas: médias obtidas para o efeito do beneficiamento (dados transformados em arc sen $\sqrt{\mathrm{P}} 7 \overline{100})$ e a diferença mínima significativa (d.m.s.) ao nível de $5 \%$ de probabilidade ............. 46

QUADRO 21 - Sementes Carunchadas: médias obtidas para o efeito de beneficiamento (dados transformados em arc sen $\sqrt{\mathrm{P} / \overline{100}}$ ) e a diferença mínima significativa ( $d$. m.s.) ao nível de $5 \%$ de probabilidade ........ 47

QUADRO 22 - Sementes com Microorganismos: médias obtidas para o efeito do beneficiamento (dados transformados em arc sen $\sqrt{\mathrm{P}} 7 \overline{100})$ e a diferença mínima significativa (d.m.s.) ao nível de $5 \%$ de probabilidade ....... 48 
1.

1. RESUMO

Os pesquisadores que trabalham com feijão são unânimes em apresentar a má qualidade das sementes utilizadas pelos 1avradores, como una das principais responsáveis pela baixa produtivi dade do feijoeiro no Brasil.

Diante de tal situação, o presente trabalho teve como objetivo estudar os efeitos da catação eletrônica pela cor e do tratamento fungicida, sobre a qualidade das sementes:

No presente trabalho, foram utilizadas sementes de feijão (Phaseolus vulgaris L.), cultivar Rosinha G-2, procedentes do Instituto Agronômico de Campinas, Estado de São Paulo. As sementes, apōs serem beneficiadas através de uma mãquina de ventilador e peneiras, foram submetidas a cinco catações eletrônicas, por uma se 
lecionadora eletrônica de fabricação nacional, "SELETRON" - SM - 500, pertencente ao Departamento de Agricultura e Horticultura da Escola Superior de Agricultura "Luiz de Queiroz", da Universidade de São Paulo (D.A.H./ESALQ/USP), e ainda tanto as sementes catadas eletronicamente como as sementes não catadas, foram tratadas com fungicida, a fim de se verificar seus efeitos.

Os efeitos da catação eletrônica, bem como do tratamento fungicida das sementes, foram avaliados através dos testes de germinação, primeira contagem de germinação, envelhecimentó rápido, porcentagem de emergência de plântulas, sobrevivência e ainda proce deu-se uma análise visual dos materiais, tanto os catados eletronica mente como os não catados, separando-se as sementes sem manchas, se mentes com mancha de levedura, sementes com outras manchas, sementes enrugadas, sementes carunchadas e sementes com microorganismos. Com a análise e interpretação dos resultadios, pode- se concluir que: a selecionadora eletrônica foi capaz de separar as sementes manchadas das não manchadas; não houve efeito do número de catações sobre a qualidade das sementes; as sementes descartadas pela máquina foram sempre de qualidade inferior; houve efeito benéfico do tratamento fungicida na primeira contagem de ger minação e sobrevivência das plantas. 
2. INTRODUÇÃO

A selecionadora eletrônica è uma máquina que, apesar de jā existir hā algum tempo, pouca coisa se sabe a seu respeito;is to talvez possa ser explicado porque a sua maior aplicação estā nas empresas privadas que não divulgam os resultados de suas pesquisas. o princípio de funcionamento dessa máquina se baseia na comparação cromática, isto é, faz a seleção das sementes após se tenha optado por um determinado padrão de cor, e as sementes que es tiverem fora desse padrão são descartadas pela máquina.

Sabe-se que um dos maiores entraves que a cultura do feijoeiro enfrenta são as doenças, e que algumas delas, além de serem transmissíveis pelas sementes, chegam a provocar deformações e manchas sobre o tegumento das mesmas. Como.no processo de beneficia mento de sementes de feijão 'comumente são empregadas as máquinas de 
ventiladores e peneiras e mesa gravitacional, sementes portadoras de manchas dificilmente são eliminadas; daí surgir a possibilidade do emprego da selecionadora eletrônica como uma maneira de descartar essas sementes após serem beneficiadas pelas máquinas citadas anteriormente.

Atualmente, um assunto que vem sendo bastante debati do pelos pesquisadores é a viabilidade ou não do tratamento de sementes, pois a decisão de tratā-las geralmente é a mais simples,mui to embora não se possa afirmar que o fungicida está sendo efetivo ou está apenas onerando ainda mais o custo de produção de cultura. De qualquer forma, o tratamento das sementes $\overrightarrow{\mathrm{e}}$ uma maneira de se ga rantir um bom "stand", por isso alguns agricultores optam por sua ap1icação.

Embora os assuntos comentados anteriormente sejam do conhecimento dos pesquisadores, pouco tem sido estudado, sendo assim, o presente trabalho teve por objetivo estudar os efeitos da ca tação eletrônica pela cor e do tratamento fungicida sobre a qualida de da semente de feijão (Phaseolus vulgaris L.). 
Um dos principais fatores responsāveis pela baixa produtividade do feijoeiro no Brasil (550 kg dados do I.B.G.E.,1977), é a qualidade das sementes utilizadas pelos lavradores. Recentemente, CHAMBERLAIN e GRAY (1974) e MENTEN (1978) relataram o efeito das condições sanitārias das sementes, afetando componentes da qualidade e consequentemente a produtividade.

Segundo VIEIRA (1967), o feijoeiro é atacado por nada menos que quatro moléstias, que são transmissíveis pelas sementes, quais sejam: bacteriose, causada por Xanthomonas phaseoli; antracnose, causada por Colletotrichum lindemuthianum; podridão-cinzenta-do-caule, causada por Macrophomina phaseoli e mosaico comum causada por vírus. As sementes atacadas por antracnose apresentam man chas em ligeiras depressões de tamanhos variāveis, desde pequenos 
pontos atē lesões que cobrem boa porção da semente, manchas amarela das pardacentas ou enegrecidas, dependendo da cor do tegumento da se mente infeccionada. Sementes infectadas por Kanthonomas phaseoli per dem sua coloração típica, se enrugam, tomam um brilho de aspecto en vernizado ou podem não apresentar nenhum sintoma (KIMATI, 1971). Uma outra doença que merece ser destacada é a mancha de levedura, causa da pelo fungo Nematospora coryli que, embora não seja transmitida por sementes, apresenta como um dos seus sintomas manchas sobre o tegumento das sementes. Segundo PARADELA FILHO (1971), até agora não se deu a devida importância a essa doença, porém, MENTEN et alii(1979) fazem referência de que $\mathrm{j} \bar{a}$ foi constatada sua presença em até $100 \%$ em amostras de sementes.

A razão pela qual apenas se enfatizou as doenças que apresentam como um dos sintomas manchas sobre o tegumento das semen tes, se deve ao fato de que a catação eletrônica se baseia na compa ração cromática. A máquina que realiza esse trabalho é dotada de uma câmara de anālise onde as sementes são analisadas e as que esti verem fora do padrão pré-determinado são descartadas. Maiores deta1hes sobre o funcionamento da máquina encontram-se em Material e Métodos.

Com relação ao tratamento fungicida,pode-se observar que os resultados das pesquisas são um tanto controvertidos. Por exemplo, CONN INGHAM (1944) e WALTER (1955), estudando vários fungicidas em sementes de feijão de Lima, observaram que nas condições 
do experimento (baixa temperatura e alta umidade), os fungicidas não promoveram aumento de produção; por sua vez,ELLIS et alii (1976) tra taram de sementes de feijão apresentando grande porcentagens de fun gos e baixa porcentagem de germinação e obtiveram resultados benéfi cos, isto é, o tratamento das sementes promoveu um aumento na porcentagem de germinação. Resultados comparáveis aos de ELLIS et alii (1976) foram obtidos por MARCOS FILHO e PERRI JUNIOR (1977).

VIEIRA (1960) considera difícil o controle dos fungos causadores das podridões das raízes dos feijoeiros e como medida a fim de reduzir os danos, sugere o tratamento das sementes. Moo re e Conover, citados por VIEIRA (1960), mostraram que o PCNB (pentacloronitrobenzeno) aplicado às sementes e no solo reduziram significativamente as infecções causadas por Rhizoctonia soloni; ainda VIEIRA (1960) verificou que a podridão das sementes causadas por es pécies de Pythium, Fusarium e Rhizoctonia puderam ser controladas com êxito mediante o tratamento das sementes, sendo o Orthocide 75 (CAPTAN) o fungicida mais eficiente. Por outro 1ado, CARVALHO e NAKAGAWA (1980) afirmam que nas condições climáticas do Brasil Central, o tratamento com fungicida é dispensável ou, pelo menos, menos necessārio do que em países de clima temperado.

No processo de beneficiamento de sementes de feijão, comumente são empregadas as máquinas de ventiladores e peneiras e mesa gravitacional; essas fazem a remoção das palhas, sementes de plantas daninhas e de outras espécies cultivadas, terra, pó, frag- 
mentos vegetais e, ainda, separações por peso das sementes. Porém verifica-se que as sementes manchadas dificilmente são separadas das boas sementes atravēs dessas máquinas. Daí a razão de algumas Insti tuições de Pesquisas lançarem mão da catação manual dessas sementes, com a finalidade de melhorar as qualidades dos lotes de sementes, principalmente daqueles de sementes básicas.

Consultando-se a literatura sobre pesquisas concernentes a catação manual e eletrônica de sementes de feijão, constatou-se que são praticamente inexistentes e, dentre os poucos trabalhos encontrados, observou-se que principalmente no caso da catação manual há uma certa discordância entre os resultados obtidos pelos pesquisadores. MASCARENHAS et alii (1963) e GODOY e TOLEDO (1964) observaram que a simples catação manual das sementes de feijão favo receu a germinação como também contribuiu para a melhoria do "stand" inicial; o que mais tarde PARADELA FILHO (1971) tambëm afix ma que a catação manual de sementes de feijão, além de ser uma medi da aconselhável para o controle de certas doenças, tem uma vantagem adicional de descartar-se pelo menos em parte, outros patógenos que acompanham as sementes. Por outro lado a eficiência da catação manual das sementes é posta em dúvida por BASTOS CRUZ (1962) pois na sua opinião,a catação manual das sementes é de difícil execução e de consequências imprevisíveis, caso as condições ambientais vierem a ser favoráveis ao aparecimento de moléstias. 
Fica evidenciado que a catação manual, além de exigir um contingente de mão-de-obra bastante elevado, è uma operação bastante cansativa, onerosa e também de baixo rendimento, surgindo assim a possibilidade do emprego da selecionadora eletrônica na catação dessas sementes.

A selecionadora eletrônica pode ser utilizada no beneficiamento, tanto na pesquisa como na melhoria da qualidade das sementes. No entanto, são escassas as informações quanto ao seu emprego, isto porque, geralmente as empresas privadas, as quais são responsáveis pela sua maior utilização, não têm interesse de divulgar os resultados de suas pesquisas a respeito da máquina.

BOYD (1967) fez um estudo a fim de explorar diversas possibilidades de aplicações da selecionadora eletrônica na ärea do beneficiamento de sementes. Primeiramente estudou a eficiência da selecionadora sobre a pureza física de sementes de arroz, sorgo e algodão; observou que a selecionadora fez um excelente trabalho de remoção de contaminantes, principalmente sementes de outras cultiva res. Posteriormente, trabalhando com dois lotes de sementes de feijão, tentou melhorar o poder germinativo de ambos e observou que um dos lotes aumentou em $18 \%$ enquanto o outro em apenas $6 \%$. Ainda tentou a separação de sementes de milho em vārias tonalidades de amare 10; os resultados indicaram que a seleção pela cor pode ser uma valiosa ferramenta na seleção de sementes com alto teor de xanthofila. 
Recentemente, CUNHA e OLIVEIRA (1978) e CUNHA (1979) realizaram trabalhos com a selecionadora eletrônica em sementes de feijão. Eles estudaram o efeito da catação eletrônica e do tratamento fungicida das sementes sobre a produtividade e sanidade dos campos da Estação Experimental de Patos de Minas. Os resultados mostraram que a simples catação eletrônica promoveu o aumento da produção, po. rēm não verificaram efeitos significativos do tratamento fungicida.

A selecionadora eletrônica, apesar de jā existir há algum tempo, muito pouco tem sido estudada. Sendo assim, é preciso que seja dada maior atenção a essa máquina, pois quem sabe, ela pos sa ser um valioso instrumento que auxilie a resolver alguns dos pro blemas que ora a agricultura enfrenta. 
11.

4. MATERIAL E METODOS

4.1 - Sementes

As sementes de feijão (Phaseolus vulgaris L.) cultivar Rosinha G-2, utilizadas no presente trabalho, foram obtidas na Secção de Leguminosas do Instituto Agronômico de Campinas, Estado de São Paulo e produzidas em Campinas na safra 1977/78. Tal escolha deveu-se ao fato dessa cultivar estar entre as recomendadas atua1mente para o cultivo no Estado de São Paulo.

\section{2 - Preparo das Sementes}

As sementes adquiridas, após a colheita, foram abana das manualmente através de peneiras. Sendo assim, na Usina de Beneficiamento do Pavilhão de Tecnologia de Sementes, do D.A.H./ESALQ/ USP, procedeu-se o beneficiamento numa máquina de ventilador e pe- 
neiras, de marca Clipper, utilizando-se as seguintes peneiras de cri vos oblongos: superior $13 \times 3 / 4$ e inferior de $10 \times 3 / 4$.

Após a limpeza, o material foi pesado, homogeneizado e dividido em três porções iguais pesando aproximadamente $10 \mathrm{~kg}$ cada uma. Em seguida, foram postas em sacos de papel "Kraft" para pos terior catação eletrônica.

\section{3 - Selecionadora Eletrônica -}

A catação eletrônica foi feita por uma selecionadora eletrônica modelo SM-500, de fabricação nacional, pertencente ao D.A.H./ESALQ/USP. Esta selecionadora eletrônica faz a separação pe1o processo de comparação cromática, separando aquelas sementes que apresentam cores indesejāveis.

Seu funcionamento pode ser resumido da seguinte maneira: as sementes a selecionar, carregadas na tremonha alimentadora da máquina, são encaminhadas por um vibrador eletromagnētico a uma correia transportadora dotada de velocidade linear constante. A disposição e a velocidade da transportadora são tais que as sementes nela se enfileiram uma após a outra. Ao fim da correia, as sementes caem no interior de uma câmara de análise; esta intensamente iluminada, incorpora duas objetivas óticas a dois fundos de referên cia, sendo a semente inspecionada pelas objetivas contra os fundos de referência. 0 contraste da semente com o fundo de referência,tra duzido em termos de quantidade de luz, è enviado pelo sistema ótico 
da objetiva à célula fotoelétrica. Esta impressionada pela luz, emi te um sinal correspondente ao contraste observado, sinal este que é amplificado e dirigido a um circuito eletrônico, o qual determinará se a semente examinada deverá prosseguir em sua trajetória normal ou será expulsa. Caso deva ser expulsa, a decisão é comunicada ao circuito de retardo que retém o sinal até que a semente atinja a saída da câmara. Após esse tempo o sinal é passado ao circuito das ejetoras o qual providencia o acionamento da vālvula eletromagnética e carregada da expulsão das sementes indesejāveis. A ejetora,com um forte sopro, desvia a semente defeituosa da sua trajetória norma1, encerrando-se aí o ciclo da operação.

A regulagem da selecionadora foi feita da seguinte maneira:

a) fundo de contraste: número 350;

b) potenciômetro de sensibilidade: levemente atenuado;

c) vazão: 1;

d) pressão do ar: 45 1ibras;

e) no painel, foi utilizada apenas a seleção de escuro, manten do-se desligada a chave de seleção de claro;

f) as regulagens dos canais foram feitas individualmente, de tal forma que:

- câmara 1 cana1 A: posição 4;

- câmara 1 cana1 B: posição 2;

- câmara 2 canal A: posição 1,5; 
- câmara 2 canal B: posição 1,5;

- câmara 3 canal A: posição 3,0;

- câmara 3 canal B: posição 3,0.

\section{4 - Catação Eletrônica}

Cada uma das porções de $10 \mathrm{~kg}$ de sementes foi submetida separadamente a cinco catações como se descreve a seguir: reti rou-se uma amostra de $1,5 \mathrm{~kg}$ para se constituir na testemunha e o material restante foi submetido sucessivamente à catação eletrônica, sendo retiradas amostras de $1,5 \mathrm{~kg}$ de cada uma das cinco catações. Posteriormente as sementes descartadas nas cinco catações foram reu nidas numa única porção, para serem submetidas às diversas análises de 1aboratório.

\section{5 - Ambiente de Conservação}

0 material selecionado foi expurgado com Phostoxin (Fosfato de alumínio 56\%) e tratado com o inseticida Malagran (4\% de malathion) nas dosagens recomendadas pelo fabricante.

As sementes, após o expurgo e tratamento com o inseticida foram armazenadas em câmara seca do Laboratório de Sementes do D.A.H./ESALQ/USP, regulada para a umidade relativa de $35 \%$ e temperatura $25^{\circ} \mathrm{C}$ a fim de serem conservadas para posteriores análises. 


\section{6 - Tratamento Fungicida}

Por ocasião da instalação dos testes de laboratório todo o material selecionado individualmente foi dividido mecanicamente atravēs do divisor de solo em duas partes aproximadamente iguais. Uma das partes foi tratada com o fungicida Rhodiauran (70\% TMTD) e a outra não foi tratada. Desta forma, foram constituídos os seguintes tratamentos para anālises, tanto em laboratório como para o ensaio de campo:
a) testemunha com tratamento fungicida;
b) testemunha sem tratamento fungicida;
c) descarte com tratamento fungicida;
d) descarte sem tratamento fungicida;
e) uma catação com tratamento fungicida;
f) uma catação sem tratamento fungicida;
g) duas catações com tratamento fungicida;
h) duas catações sem tratamento fungicida;
i) três catações com tratamento fungicida;
j) três catações sem tratamento fungicida;
1) quatro catações com tratamento fungicida;
m) quatro catações sem tratamento fungicida;
n) cinco catações com tratamento fungicida;
o) cinco catações sem tratamento fungicida. 


\section{7 - Testes de Laboratörio}

Os testes de germinação e de vigor foram realizados no Laboratório de Sementes do D.A.H./ESALQ/USP no período de 01 de setembro de 1978 a 10 de janeiro de 1979.

\subsection{1 - Testes de germinação}

Nos testes de germinação seguiu-se as prescrições in dicadas pelas Regras para Anālises de Sementes (BRASIL, M.A., 1976). 0 substrato utilizado foi o papel toalha especial, de fabricação norte-americana, sem lavagem prévia, umedecido no momento da instalação dos testes. Utilizou-se germinador de marca Burrows, regulado para a temperatura alternada de $20-30{ }^{\circ} \mathrm{C}$.

\subsection{2 - Testes de vigor}

o vigor das sementes foi avaliado através da primeira contagem de germinação e envelhecimento rāpido.

a) Primeira contagem de germinação

Este teste foi efetuado em conjunto com o teste padrão de germinação e constou do registro da porcentagem de plântulas nomais verificadas na contagem realizada no quinto dia após a instalação de cada teste, conforme BYRD e DELOUCHE (1971). 
b) Envelhecimento räpido

Neste teste seguiu-se o procedimento descrito por FA GUNDES (1974); as sementes foram submetidas às condições da Câmara de Envelhecimento Rāpido, marca DE LEO, à temperatura de $42{ }^{\circ} \mathrm{C}$ e $100 \%$ de umidade relativa por 72 horas. Vencido o período de permanência na câmara, as sementes foram colocadas para germinar da forma descrita no ítem 4.7.1. As contagens foram feitas após o quinto dia da instalação dos testes.

\subsection{3 - Outras determinações}

Apōs as sementes serem catadas eletronicamente, toma ram-se amostras de aproximadamente $0,25 \mathrm{Kg}$ de cada uma das catações e do material descartado, sendo estas submetidas a uma anālise visual onde procedeu-se um exame minucioso das sementes, separando-se aque las sem manchas, com mancha de levedura, outras manchas, enrugadas, carunchadas, e com microorganismos, isto $\bar{e}$, a fim de melhor caracte rizar o material.

O estado sanitário das sementes foi avaliado atravēs do método de ágar: após a assepcia superficial (hipoclorito de sódio $2,5 \%$ por 5 minutos), as sementes foram colocadas sobre BSA $(0,2 \mathrm{Kg}$ de batata, $0,1 \mathrm{Kg}$ de sacarose,0,18Kg de ágar, água destilada q.s.p. $1000 \mathrm{~m} 1$ ), ( 5 sementes por placa de Petri) e mantidas a $25{ }^{\circ} \mathrm{C}$ sob luz fluorescente a $0,4 \mathrm{~m}$ da superfície das placas ( 12 horas do escu ro) durante 7 dias (MENTEN, 1978 e LASCA, 1978). 


\section{8 - Ensaio de Campo}

0 experimento de campo foi instalado no dia 11 de ja neiro de 1979, no campo experimental do D.A.H./ESALQ/USP.

0 delineamento experimental adotado foi o de blocos ao acaso com três repetições, e os testes constariam de: porcentagem de emergência de plântulas e sobrevivência.

4.8.1 - Porcentagem de emergência de plântulas

Neste teste seguiu-se o procedimento descrito por FELDMANN (1976) .

O terreno, depois de convenientemente preparado, foi sulcado e dividido em parcelas de 4 linhas de 3 m cada uma, espaçadas de 0,3m; foram semeadas 100 sementes em cada 1 inha.

No vigésimo dia após a semeadura, quando cerca de $85 \%$ das plântulas jā se apresentavam desprovidas dos cotiledones, fez-se a contagem das que emergiram.

\subsection{2 - Sobrevivência}

Apōs trinta e quatro dias da contagem de emergência, efetuou-se uma nova contagem das plantas sobreviventes, isto a $\mathrm{fim}$ de constatar-se quantas plantas realmente sobreviveram. 


\section{9 - Mētodos Estatisticos}

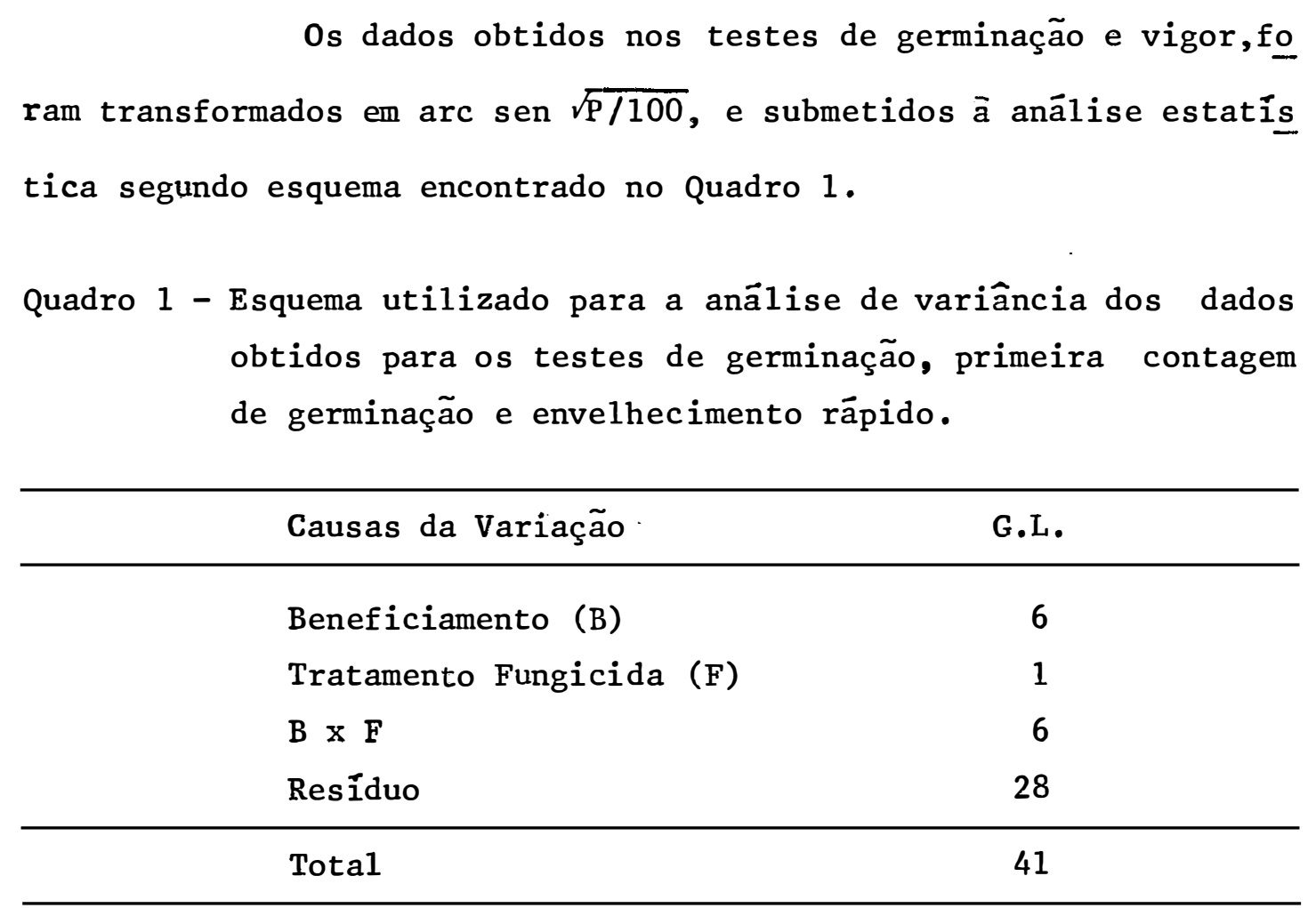

Utilizou-se o método de Tukey para a comparação das médias do beneficiamento, do tratamento fungicida e de suas interações.

Os dados obtidos das sementes sem manchas, sementes com mancha de levedura, sementes com outras manchas, sementes enrugadas e sementes carunchadas, foram transformados em arc sen $\sqrt{\mathrm{P}} \overline{100}$, e submetidos a análise estatística segundo esquema que pode ser observado no Quadro 2. 
Quadro 2 - Esquema utilizado para a anālise de variância dos dados obtidos nas sementes sem manchas, sementes com mancha de levedura, sementes carunchadas, sementes enrugadas e sementes com microorganismos.

\begin{tabular}{lr}
\hline Causas da Variação & G.L. \\
\hline Beneficiamento (B) & 6 \\
Resíduo & 14 \\
\hline Total & 20 \\
\hline
\end{tabular}

Utilizou-se o método de Tukey para comparação das mé dias do beneficiamento.

Os dados obtidos nos testes de porcentagem de emergência de plântulas e sobrevivência, foram transformados em arc sen $\sqrt{\mathrm{P} 7 \overline{100}}$, e submetidos a anālise estatística segundo esquema encontra do no Quadro 3.

Quadro 3 - Esquema utilizado para a análise de variância dos dados obtidos para os testes de porcentagem de emergência de plântulas e sobrevivência.

\begin{tabular}{lc}
\hline Causas da Variação & G.L. \\
\hline Beneficiamento (B) & 6 \\
Tratamento Fungicida (F) & 1 \\
B x F & 6 \\
Blocos & 2 \\
Resíduo & 26 \\
\hline Total & 41 \\
\hline
\end{tabular}


Utilizou-se o método de Tukey para comparação das mé dias do beneficiamento, tratamento fungicida e de suas interações. 
5. RESULTADOS

\section{1 - Testes de Laboratōrio}

Os valores de $F$ e os coeficientes de variação obtidos nos testes de germinação, primeira contagem de germinação e envelhecimento rápido acham-se reunidos no Quadro 4.

\section{1 .1 - Germinação}

Examinando-se os resultados da anālise de variância no Quadro 4 observa-se que o beneficiamento e a interação beneficia mento dentro de tratamento fungicida revelaram significância ao níve1 de $1 \%$ de probabilidade.

Âs médias obtidas para o efeito do beneficiamento e a diferença mínima significativa ao nível de $5 \%$ de probabilidade en 
contram-se no Quadro 5. 0 exame do referido quadro permite verificar que a menor média obtida no teste de germinação foi a do descar te e que esta diferiu significativamente dos demais beneficiamentos. Com exceção do descarte, os outros beneficiamentos não diferiram en tre si.

As médias obtidas para o efeito da interação beneficiamento dentro de tratamento fungicida e a diferença mínima significativa ao nível de 5\% de probabilidade encontram-se no Quadro 6. 0 exame do referido quadro permite verificar que o descarte das sementes apresentou menor porcentagem de germinação do que os demais beneficiamentos que, por sua vez, apresentaram um comportamento semelhante. Para as sementes não tratadas, esta porcentagem foi menor apenas em relação às catações, uma vez que o descarte apresentou com portamento semelhante em relação à testemunha, ao passo que as cata ções apresentaram comportamento semelhante.

\subsection{2 - Primeira contagem de germinação}

Examinando-se os resultados da anälise de variância no Quadro 4, observa-se que o beneficiamento,o tratamento fungicida e a interação do beneficiamento dentro do tratamento fungicida mostraram significância ao nível de $1 \%$ de probabilidade.Jā na interação tratamento fungicida dentro do beneficiamento, a testemunha e o descar te apresentaram valores de F significativos ao nível de $1 \%$ de proba 
bilidade, e que uma, duas, e quatro cataçoes foram significativas ao nive1 de $5 \%$ de probabilidade.

As médias obtidas para o efeito de beneficiamento e a diferença mínima significativa ao nível de $5 \%$ de probabilidade en contram-se no Quadro 7. 0 exame do referido quadro revela que a tes temunha e o descarte não diferiram significativamente entre si e fo ram inferiores aos demais beneficiamentos, os quais também apresentaram comportamento semelhante entre si.

As médias obtidas para o efeito do tratamento fungicida constam do Quadro 8. No exame do referido quadro observa-se que houve superioridade das sementes tratadas sobre as sementes não tra tadas.

As médias obtidas para o efeito da interação tratamento fungicida dentro de beneficiamento, e a diferença mínima significativa, ao níve1 de $5 \%$ de probabilidade, encontram-se no Quadro 9. 0 exame do referido quadro permite verificar que, com exceção dos beneficiamentos três e cinco catações, as sementes tratadas foram superiores às sementes não tratadas.

As médias obtidas para o efeito da interação beneficiamento dentro de tratamento fungicida e a diferença mínima significativa, ao níve1 de 5\% de probabilidade, encontram-se no Quadro 10. 0 exame do referido quadro permite verificar que, com exceção da testemunha, todos os beneficiamentos diferiram significativamente do descarte, tanto para as sementes tratadas como para as sementes não 
tratadas. Entre as sementes tratadas, as cinco catações não diferiram significativamente da testemunha; $j a ̄$ nas sementes não tratadas, as cinco catações, que não diferiram entre si, foram superiores à tes temunha.

\section{1 .3 - Envelhecimento räpido}

0 resultado da anālise de variância desse teste não acusou valor de F significativo, tanto para o efeito do beneficiamento, como para o tratamento fungicida. As médias referentes ao bene ficiamento podem ser observadas no Quadro 11.

\section{2 - Ensaio de Campo}

Os valores de $\mathrm{F}$ e os coeficientes de variação obtidos nas porcentagens de emergência de plântulas e sobrevivências, acham-se reunidos no Quadro 12 .

\subsection{1 - Porcentagem de emergència de plântulas}

Examinando-se os resultados da anālise de variância no Quadro 12, observa-se que o beneficiamento mostrou significância ao nível de $1 \%$ de probabilidade.

As médias obtidas para o efeito do beneficiamento e a diferença mínima significativa, ao nível de $5 \%$ de probabilidade, 
encontram-se no Quadro 13. 0 exame do referido quadro permite verificar que o descarte apresentou uma menor porcentagem de emergência de plântulas do que os demais beneficiamentos, que por sua vez não diferiram entre si.

\subsection{2 - Sobrevivência}

Examinando-se os resultados da anālise de variância no Quadro 12, observa-se que o beneficiamento e o tratamento fungici da mostraram significância, ao nível de $5 \%$ de probabilidade.

As médias obtidas para o efeito do beneficiamento e a diferença mínima significativa, ao nível de $5 \%$ de probabilidade, encontram-se no Quadro 14. 0 exame do referido quadro permite verificar que o descarte foi inferior apenas a duas catações, sendo que os demais beneficiamentos apresentaram um comportamento semelhante.

As mēdias obtidas para o efeito do tratamento fungici da encontram-se no Quadro 15. 0 exame do referido quadro permite ve rificar que houve superioridade das sementes tratadas sobre as sementes não tratadas.

\section{3 - Outras Determinações}

Os valores de $\mathrm{F}$ e os coeficientes de variação obtidos para sementes sem manchas, sementes com mancha de levedura, se mentes com outras manchas, sementes enrugadas, sementes carunchadas 
e sementes com microorganismos, acham-se reunidos no Quadro 16.

\subsection{1 - Sementes sem manchas}

Examinando-se o resultado da anālise de variância no Quadro 16 , observa-se que o beneficiamento mostrou significância ao nível de $1 \%$ de probabilidade.

As médias obtidas para o efeito do beneficiamento e a diferença mínima significativa, ao nível de $5 \%$ de probabilidade, encontram-se no Quadro 17. 0 exame do referido quadro permite verificar que o descarte apresentou menor porcentagem de sementes sem manchas do que os demais beneficiamentos, que por sua vez tiveram um comportamento semelhante.

\subsection{2 - Sementes com mancha de levedura}

Examinando-se o resultado da anālise de variância no Quadro 16, observa-se que o beneficiamento mostrou significância ao nível de $1 \%$ de probabilidade.

As médias obtidas para o efeito do beneficiamento e a diferença mínima significativa, ao nível de $5 \%$ de probabilidade, encontram-se no Quadro 18. 0 exame do referido quadro permite verificar que o descarte apresentou maior porcentagem de sementes com mancha de levedura do que os demais beneficiamentos. Por outro lado, a testemunha, uma, quatro e cinco catações não diferiram entre 
si, porēm, apenas a testemunha foi superior a duas e a três catações, enquanto que cinco catações apresentou maior porcentagem do que três catações.

\subsection{3 - Sementes com outras manchas}

Examinando-se o resultado da anālise de variância no Quadro 16, observa-se que o beneficiamento mostrou significância ao nível de $1 \%$ de probabilidade.

As médias obtidas para o efeito do beneficiamento e a diferença mínima significativa, ao nível de $5 \%$ de probabilidade, encontram-se no Quadro 19. 0 exame do referido quadro permite verificar que o descarte apresentou maior porcentagem de sementes com outras manchas do que os demais beneficiamentos, que por sua vez ti veram um comportamento semelhante.

\section{3 .4 - Sementes Enrugadas}

Examinando-se o resultado da análise de variância no Quadro 16,observa-se que o beneficiamento mostrou significância ao nível de $1 \%$ de probabilidade.

As médias obtidas para o efeito do beneficiamento e a diferença mínima significativa, ao nível de $5 \%$ de probabilidade, encontram-se no Quadro 20. 0 exame do referido quadro permite verificar que o descarte apresentou maior porcentagem de sementes enru- 
gadas do que os demais beneficiamentos, que por sua vez não diferiram entre si.

\section{3 .5 - Sementes carunchadas}

Como se pode observar no Quadro 16, a anālise de variância dos dados de sementes carunchadas não acusou valores de $F$ significativos.

As médias obtidas para o efeito do beneficiamento e a diferença mínima significativa, ao nível de $5 \%$ de probabilidade, encontram-se reunidas no Quadro 21 .

\section{3 .6 - Sementes com microorganismos}

Examinando-se o resultado da anālise de variância no Quadro 16, observa-se que o beneficiamento mostrou significância ao nível de $5 \%$ de probabilidade.

As médias obtidas para o efeito do beneficiamento e a diferença mínima significativa, ao nível de $5 \%$ de probabilidade, encontram-se no Quadro 22. 0 exame do referido quadro permite verificar que o descarte e a testemunha não diferiram entre si, porém, apenas o primeiro foi superior aos demais beneficiamentos, que apre sentaram comportamento semelhantes entre si. 
Quadro 4 - Valores de F e coeficientes de variação obtidos nos testes de germinação, primeira contagem de germinação e envelhecimento räpido.

\begin{tabular}{|c|c|c|c|}
\hline CAUSAS DA VARIAÇÃO & $\begin{array}{c}\text { Teste } \\
\text { de } \\
\text { Germinação }\end{array}$ & $\begin{array}{l}\text { 1. Contagem } \\
\text { de } \\
\text { Germinação }\end{array}$ & $\begin{array}{l}\text { Envelhe- } \\
\text { cimento } \\
\text { Rápido }\end{array}$ \\
\hline Beneficiamento (B) & $13,02 * *$ & $25,92 * *$ & $0,61 \mathrm{~ns}$ \\
\hline Tratamento fungicida (F) & $0,57 \mathrm{~ns}$ & $55,05 * *$ & 1,29 ns \\
\hline$B \times F$ & $0,82 \mathrm{~ns}$ & $3,70 * *$ & $0,09 \mathrm{~ns}$ \\
\hline Fungicida d. testemunha & $1,41 \mathrm{~ns}$ & $32,50 * *$ & $0,16 \mathrm{~ns}$ \\
\hline Fungicida d. descarte & $0,23 \mathrm{~ns}$ & $21,80 * *$ & $0,06 \mathrm{~ns}$ \\
\hline Fungicida d. uma catação & $0,00 \mathrm{~ns}$ & $6,92 *$ & $0,50 \mathrm{~ns}$ \\
\hline Fungicida d. duas catações & $2,92 n s$ & $7,01 *$ & $0,50 \mathrm{~ns}$ \\
\hline Fungicida d. três catações & $0,26 n s$ & $2,98 \mathrm{~ns}$ & $0,00 \mathrm{~ns}$ \\
\hline Fungicida d. quatro catações & $0,61 \mathrm{~ns}$ & $5,91 *$ & $0,56 \mathrm{~ns}$ \\
\hline Fungicida d. cinco catações & $0,00 \mathrm{~ns}$ & $0,03 \mathrm{~ns}$ & $0,08 \mathrm{~ns}$ \\
\hline Beneficiamento d. tratadas & $6,01 * *$ & $6,18 * *$ & $0,53 \mathrm{~ns}$ \\
\hline Beneficiamento d. não tratadas & $7,82 * *$ & $23,43 * *$ & $0,22 \mathrm{~ns}$ \\
\hline Coeficiente de Variação (\%) & 3,85 & 3,32 & 17,00 \\
\hline
\end{tabular}

ns = não significativo;

* = significativo ao nível de $5 \%$ de probabilidade;

** = significativo ao nível de $1 \%$ de probabilidade. 


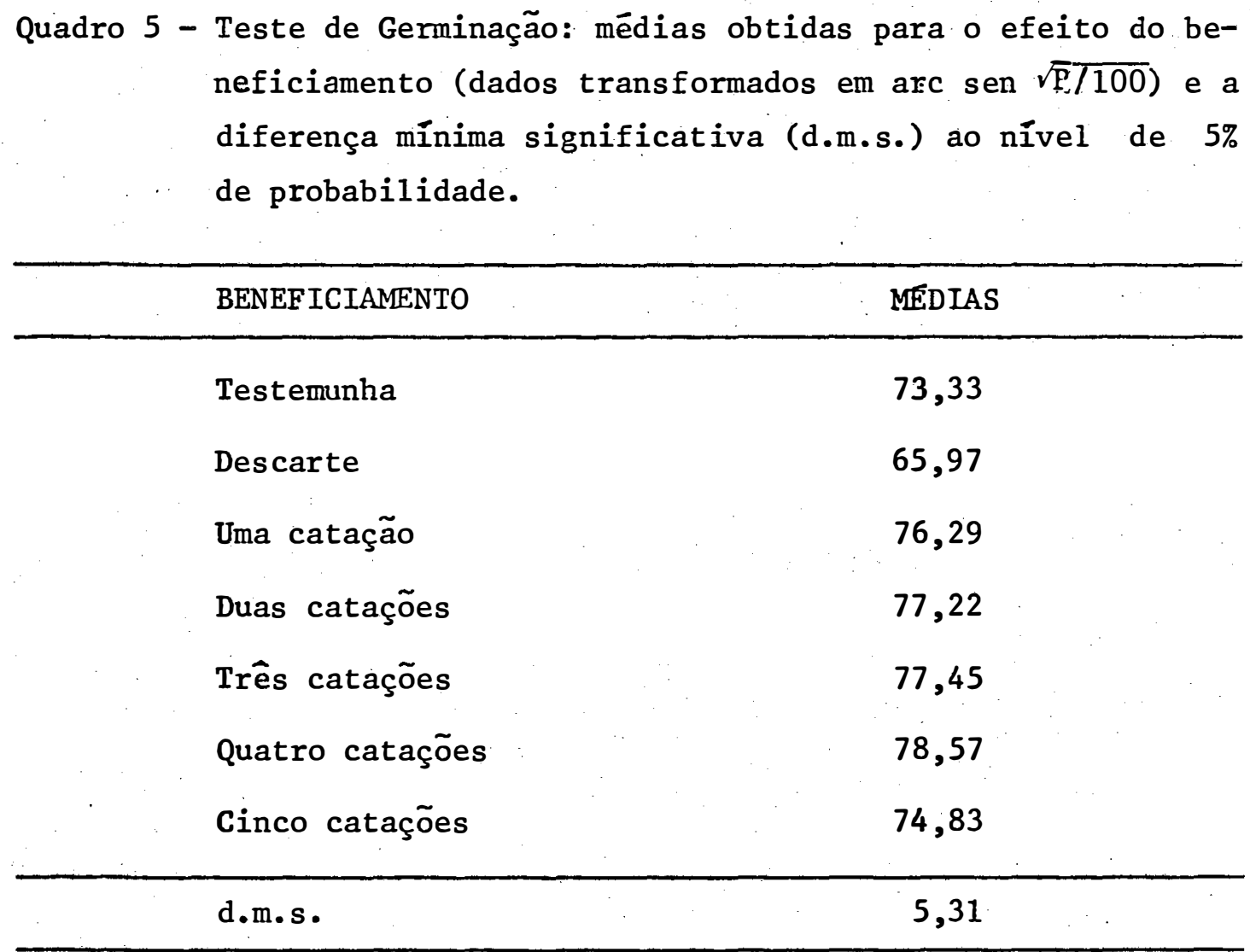




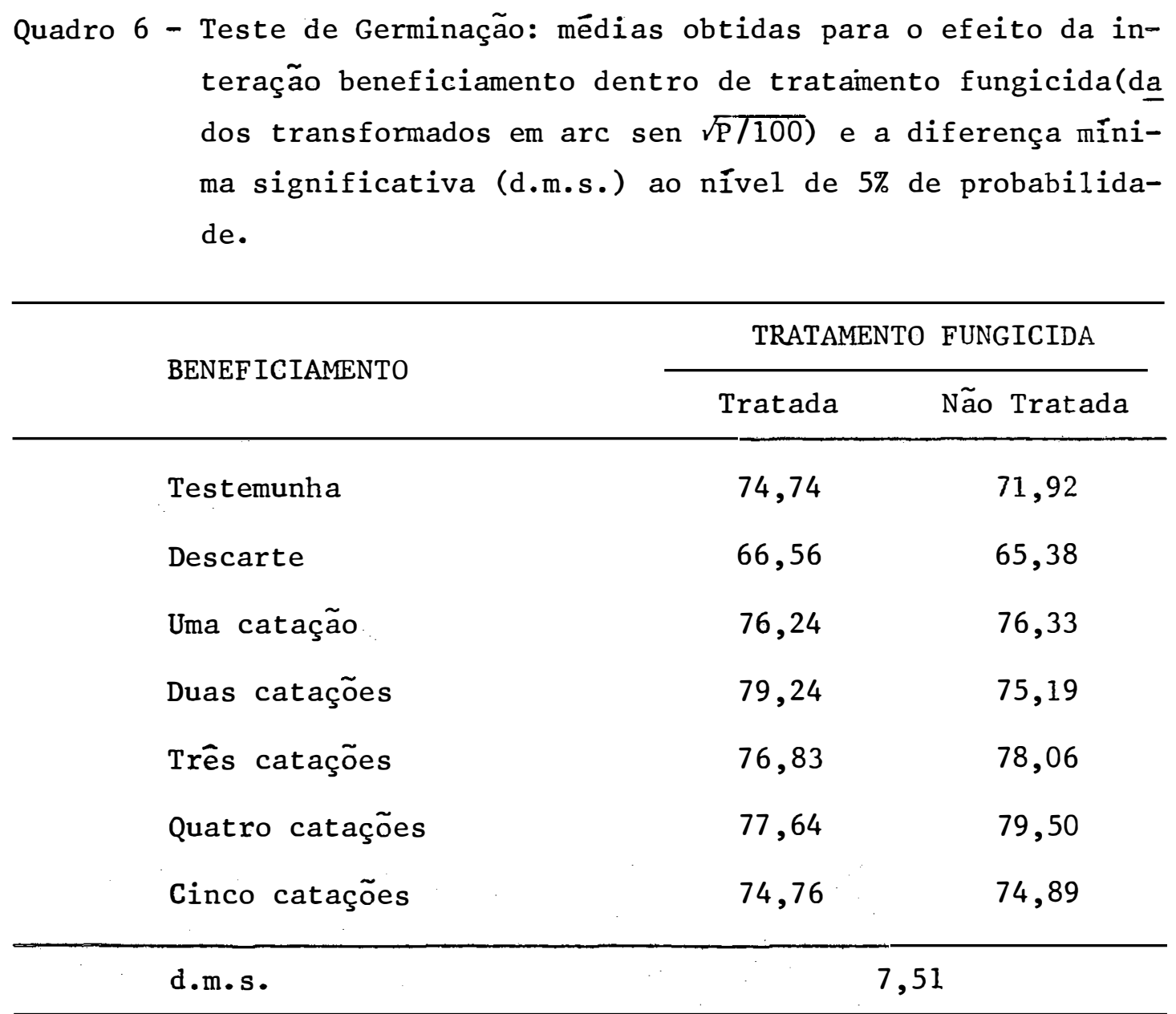


33.

Quadro 7 - Primeira Contagem de Germinação: médias obtidas para o efeito do beneficiamento (dados transformados em arc sen $\sqrt{\mathrm{P} 7 \overline{100}}$ e a diferença mínima significativa (d.m.s.) ao nível de $5 \%$ de probabilidade.

\begin{tabular}{lc}
\hline BENEF ICIAMENTO & MEDIAS \\
Testemunha & 63,16 \\
Descarte & 60,51 \\
Una catação & 69,46 \\
Duas catações & 70,81 \\
Três catações & 70,48 \\
Quatro catações & 71,72 \\
Cinco catações & 73,09 \\
\hline
\end{tabular}



Quadro 8 - Primeira Contagem de Germinação: médias obtidas para o efeito do tratamento fungicida (dados transformados em arc sen $\sqrt{\mathrm{P} / 100)}$.

\begin{tabular}{cc}
\hline \multicolumn{2}{c}{ TRATAMENTO FUNGICIDA } \\
\hline TRATADA & NÃO TRATADA \\
\hline & \\
71,06 & 65,86 \\
\hline
\end{tabular}


Quadro 9 - Primeira Contagem de Germinação: médias obtidas para o efeito da interação tratamento fungicida dentro de beneficiamento (dados transformados em arc sen $\overline{\sqrt{p / 100}}$ ) e a diferença mínima significativa (d.m.s.) ao nível de $5 \%$ de probabilidade.

\begin{tabular}{lcc}
\hline BENEF ICIAMENTO & \multicolumn{2}{c}{ TRATAMENTO FUNGICIDA } \\
\hline Testemunha & Tratada & Não Tratada \\
\hline Descarte & 68,45 & 57,86 \\
Uma catação & 64,85 & 56,17 \\
Duas catações & 71,90 & 67,02 \\
Três catações & 73,27 & 68,35 \\
Quatro catações & 72,08 & 68,88 \\
Cinco catações & 73,98 & 69,46 \\
d.m.s. & 72,92 & 73,26 \\
\hline
\end{tabular}


Quadro 10 - Primeira Contagem de Germinação: médias obtidas para o efeito da interação do beneficiamento dentro de tratamento fungicida (dados transformados em arc sen $\sqrt{\mathrm{P}} \mathrm{T100}$ ) e a diferença mínima significativa (d.m.s.) ao nível de 5\% de probabilidade.

\begin{tabular}{lcc}
\hline & \multicolumn{2}{c}{ TRATAMENTO FUNGICIDA } \\
\cline { 2 - 3 } BENEFICIAMENTO & Tratada & Não Tratada \\
\hline Testemunha & 68,45 & 57,86 \\
Descarte & 64,85 & 56,17 \\
Una catação & 71,90 & 67,02 \\
Duas catações & 73,27 & 68,35 \\
Três catações & 72,08 & 68,88 \\
Quatro catações & 73,98 & 69,46 \\
Cinco catações & 72,92 & 73,26 \\
\hline d.m.s. & & 5,89 \\
\hline
\end{tabular}


37.

Quadro 11 - Envelhecimento Rápido: médias obtidas para o efeito do beneficiamento (dados transformados em arc sen $\sqrt{\mathrm{P}} 7 \overline{100}$ ) e a diferença mínima significativa (d.m.s.) ao nível de 5\% de probabilidade.

\begin{tabular}{ll}
\hline BENEF ICIAMENTO & MEDIAS \\
\hline Testemunha & 70,19 \\
Descarte & 63,79 \\
Uma catação & 72,75 \\
Duas catações & 72,08 \\
Três catações & 72,55 \\
Quatro catações & 74,23 \\
Cinco catações & 74,84 \\
\hline d.m.s. & 22,41 \\
\hline
\end{tabular}


Quadro 12 - Valores de F e coeficientes de variação (\%) obtidos para: porcentagem de emergência de plântulas e sobrevivên cia.

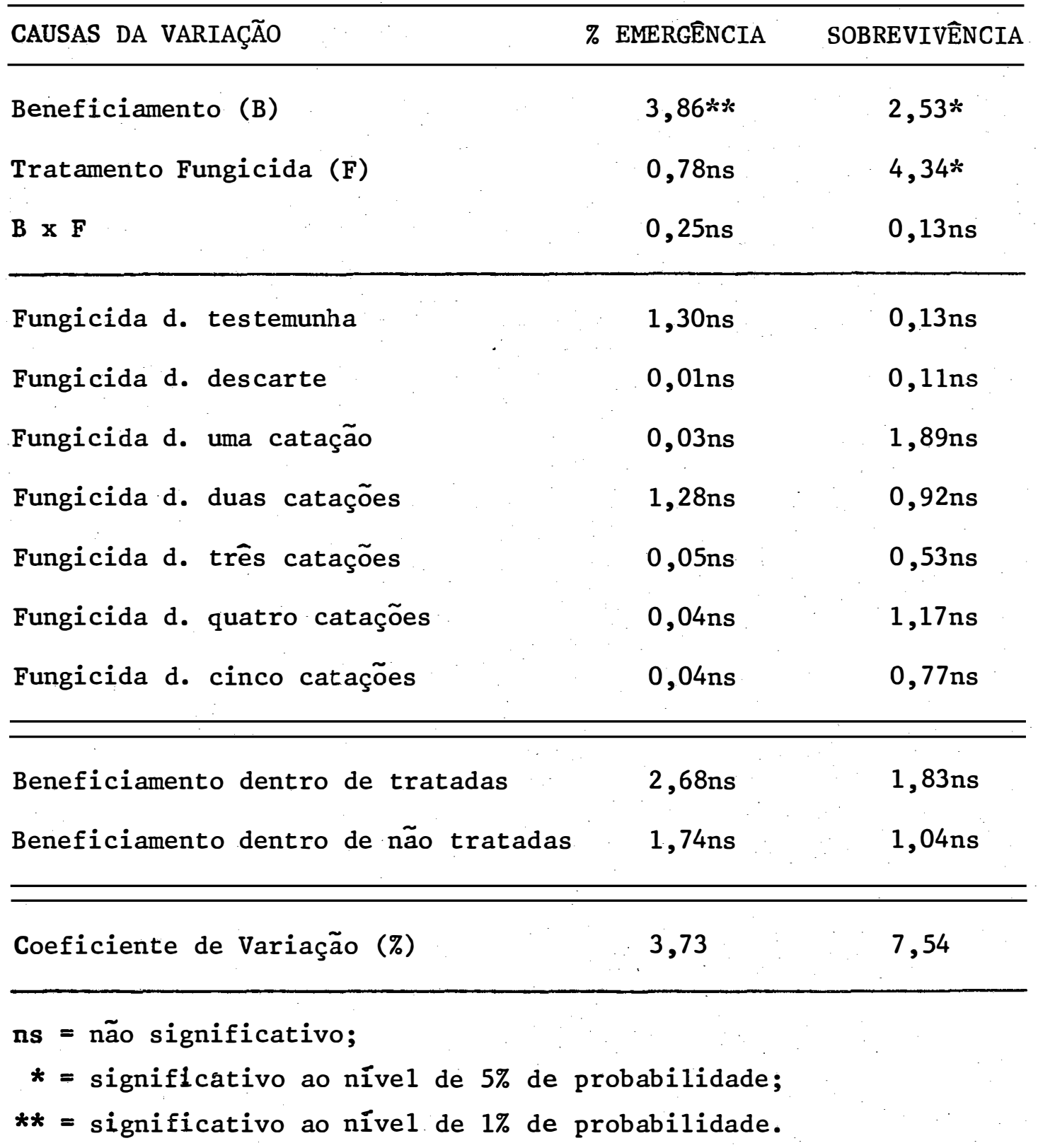


39.

Quadro 13 - Porcentagem de Emergência de Plântulas: médias obtidas para o efeito do beneficiamento (dados transformados em

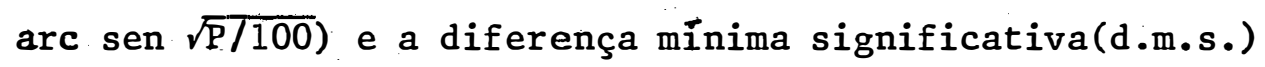
ao nível de $5 \%$ de probabilidade.

\begin{tabular}{ll}
\hline BENEFICIAMENTO & MEDIAS \\
\hline Testemunha & 72,53 \\
Descarte & 61,12 \\
Uma catação & 73,03 \\
Duas catações & 73,79 \\
Três catações & 73,49 \\
Quatro catações & 71,77 \\
Cinco catações & 73,76 \\
\hline d.m.s. & 10,23 \\
\hline
\end{tabular}


40.

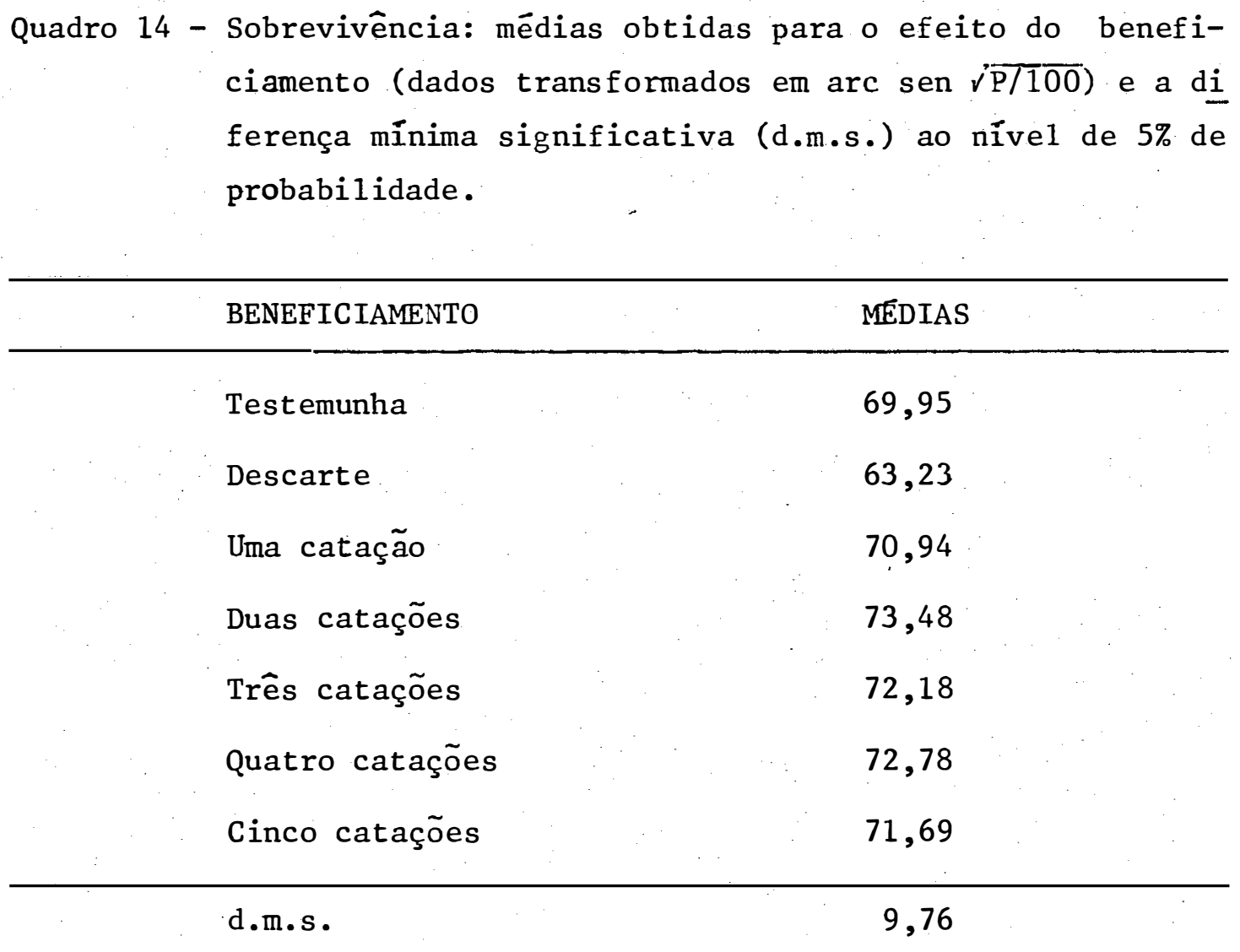


41.

Quadro 15 - Sobrevivência: mēdias obtidas para o efeito do tratamen to fungicida (dados transformados em arc sen $\sqrt{\mathrm{P} / 100}$ ).

TRATAMENTO FUNGICIDA

TRATADA

NÃO TRATADA

$72,32 \quad 68,89$


42.

Quadro 16 - Valores de F e coeficientes de variação (\%) obtidos para sementes sem manchas, sementes com mancha de levedu ra, sementes com outras manchas, sementes enrugadas, se mentes carunchadas, e sementes com microorganismos.

\begin{tabular}{lcc}
\hline CAUSAS DA VARIAÇÃO & F & C.V. (\%) \\
\hline Sementes sem manchas & $33,19 * *$ & 5,02 \\
Sementes com mancha de levedura & $18,19 * *$ & 15,08 \\
Sementes com outras manchas & $59,76 * *$ & 7,58 \\
Sementes enrugadas & $8,05 * *$ & 36,62 \\
Sementes carunchadas & $1,78 \mathrm{~ns}$ & 51,62 \\
Sementes com microorganismos & $9,71 *$ & 38,39 \\
\hline ns $=$ não significativo; & \\
$* \quad=$ significativo ao nível de $5 \%$ de probabilidade; & \\
$* *=$ significativo ao nível de $1 \%$ de probabilidade. &
\end{tabular}




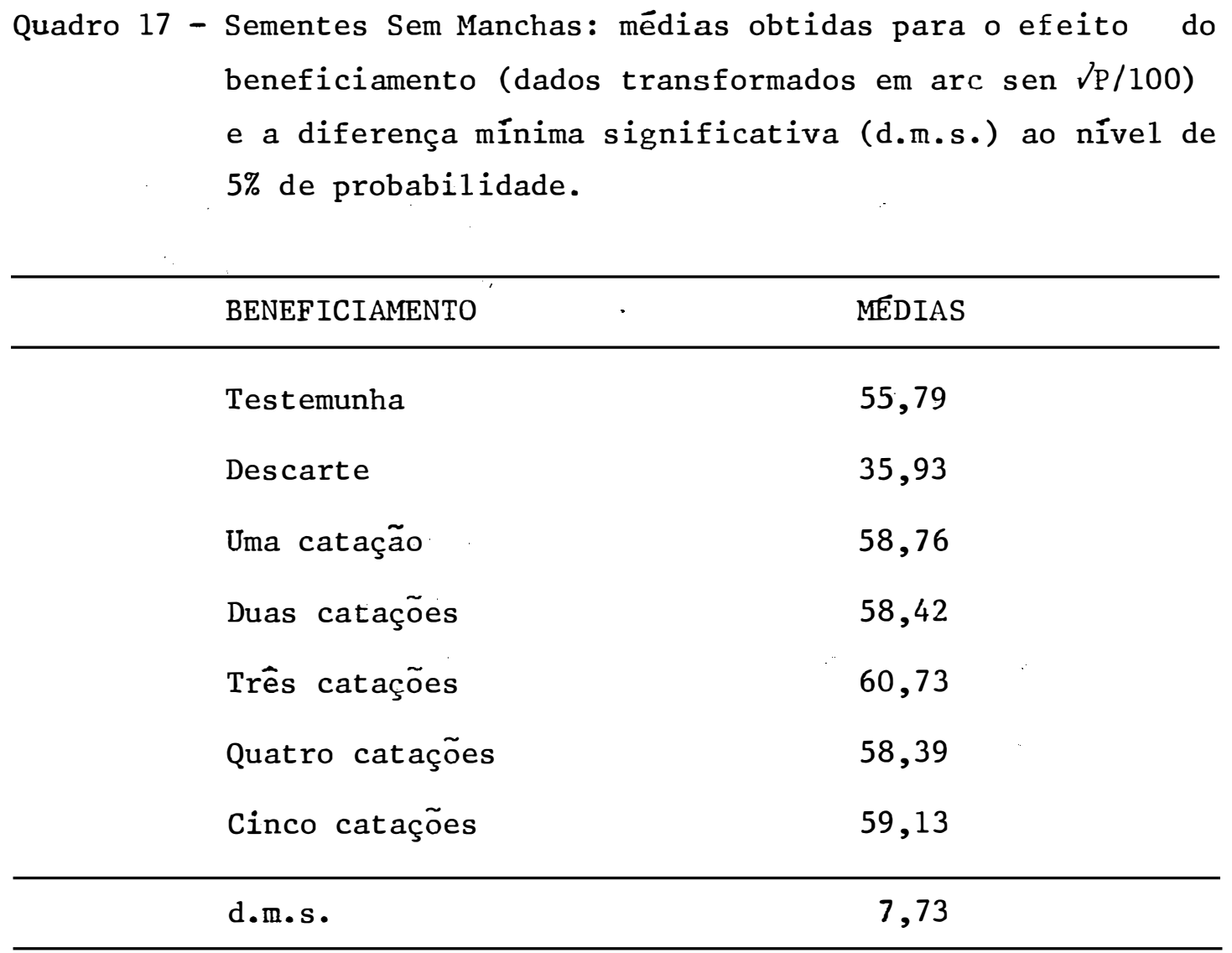


Quadro 18 - Semente com mancha de levedura: médias obtidas para o efeito do beneficiamento (dados transformados em arc sen $\sqrt{\mathrm{P} 7 \overline{100}}$ ) e a diferença mínima significativa (d.m.s.) ao nível de $5 \%$ de probabilidade.

\begin{tabular}{ll}
\hline BENEFICIAMENTO & MEDIAS \\
\hline Testemunha & 14,02 \\
Descarte & 24,68 \\
Uma catação & 12,69 \\
Duas catações & 10,83 \\
Três catações & 10,63 \\
Quatro catações & 12,82 \\
Cinco catações & 13,75 \\
\hline d.m.s. & 3,00 \\
\hline
\end{tabular}


45.

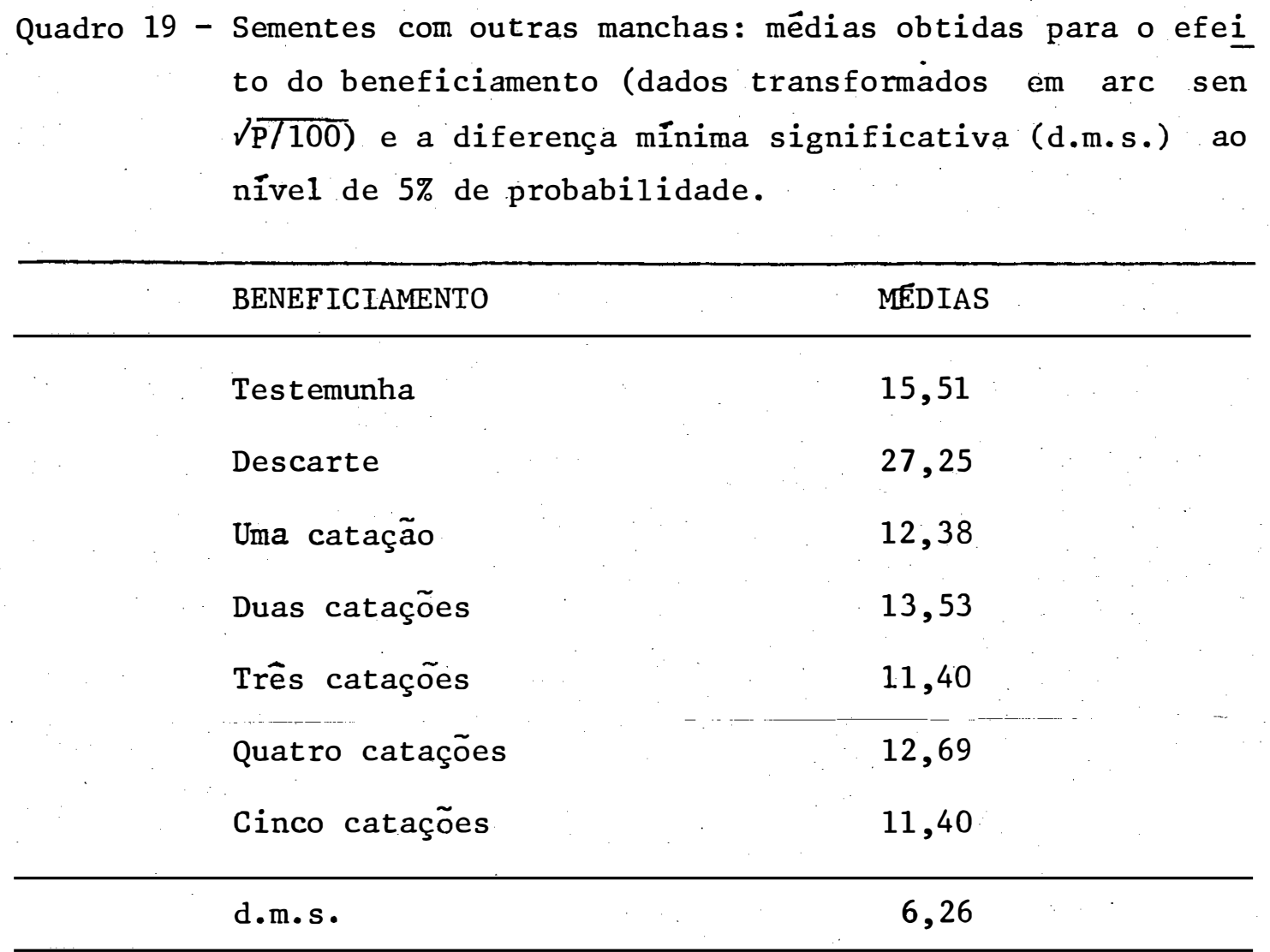


46.

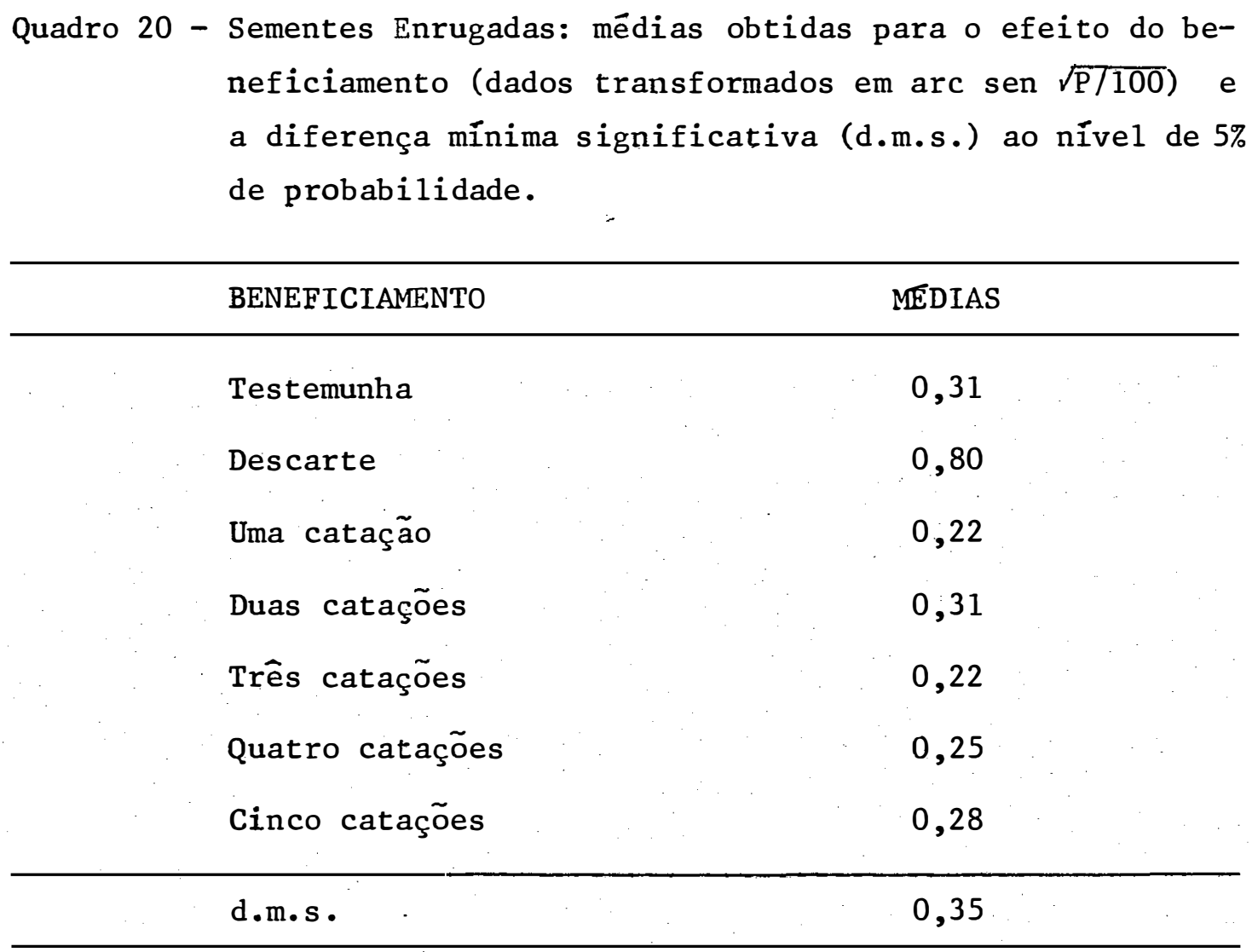


47.

Quadro 21 - Sementes Carunchadas: médias obtidas para o efeito de beneficiamento (dados transformados em arc sen $\sqrt{\mathrm{P} / 100}$ ) e a diferença mínima significativa (d.m.s.) ao nível de 5\% de probabilidade.

\begin{tabular}{lc}
\hline BENEFICIAMENTO & MEDIAS \\
\hline Testemunha & 0,14 \\
Descarte & 0,36 \\
Uma catação & 0,17 \\
Duas catações & 0,11 \\
Três catações & 0,20 \\
Quatro catações & 0,13 \\
Cinco catações & 0,24 \\
\hline d.m.s. & 0,28 \\
\hline
\end{tabular}


48.

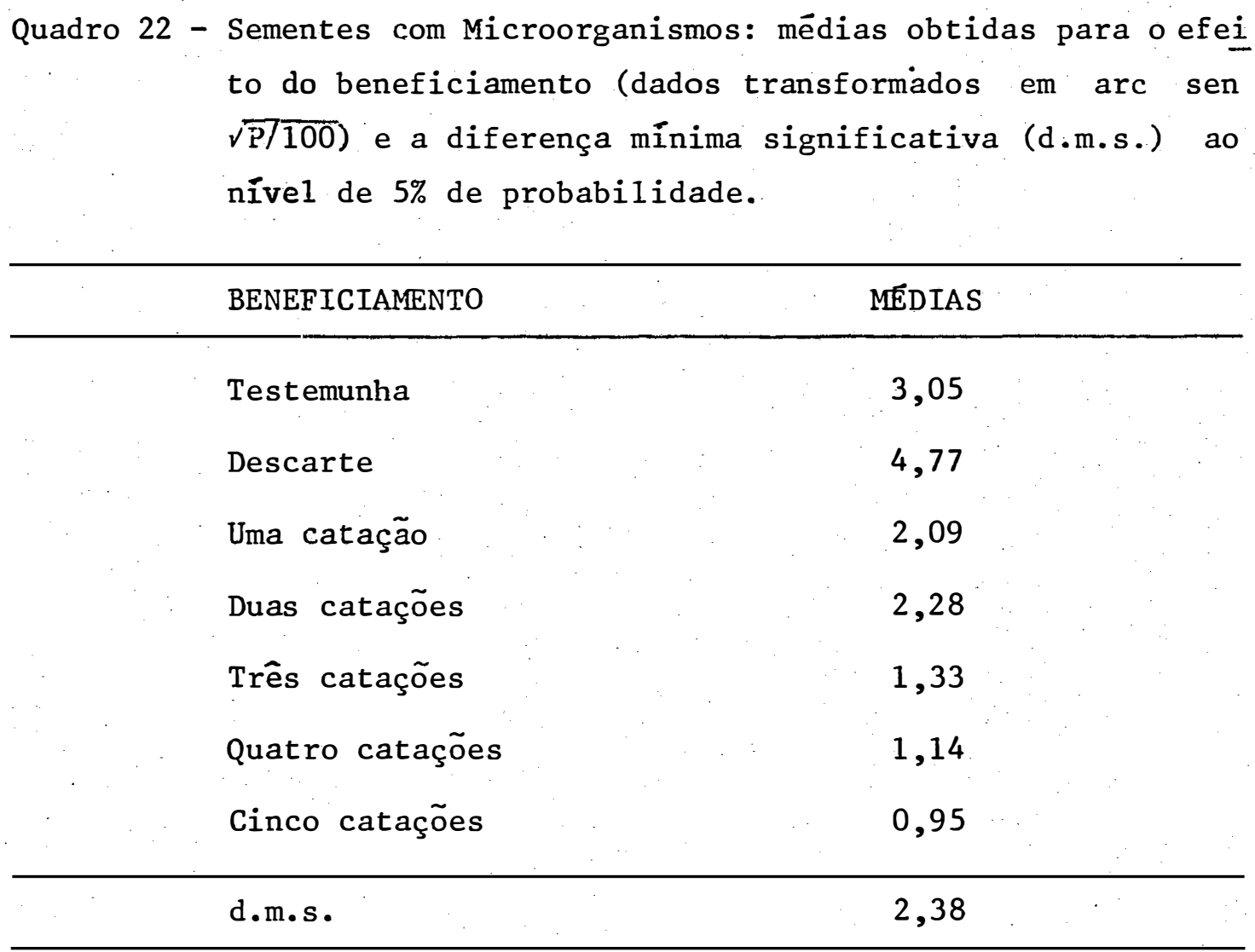



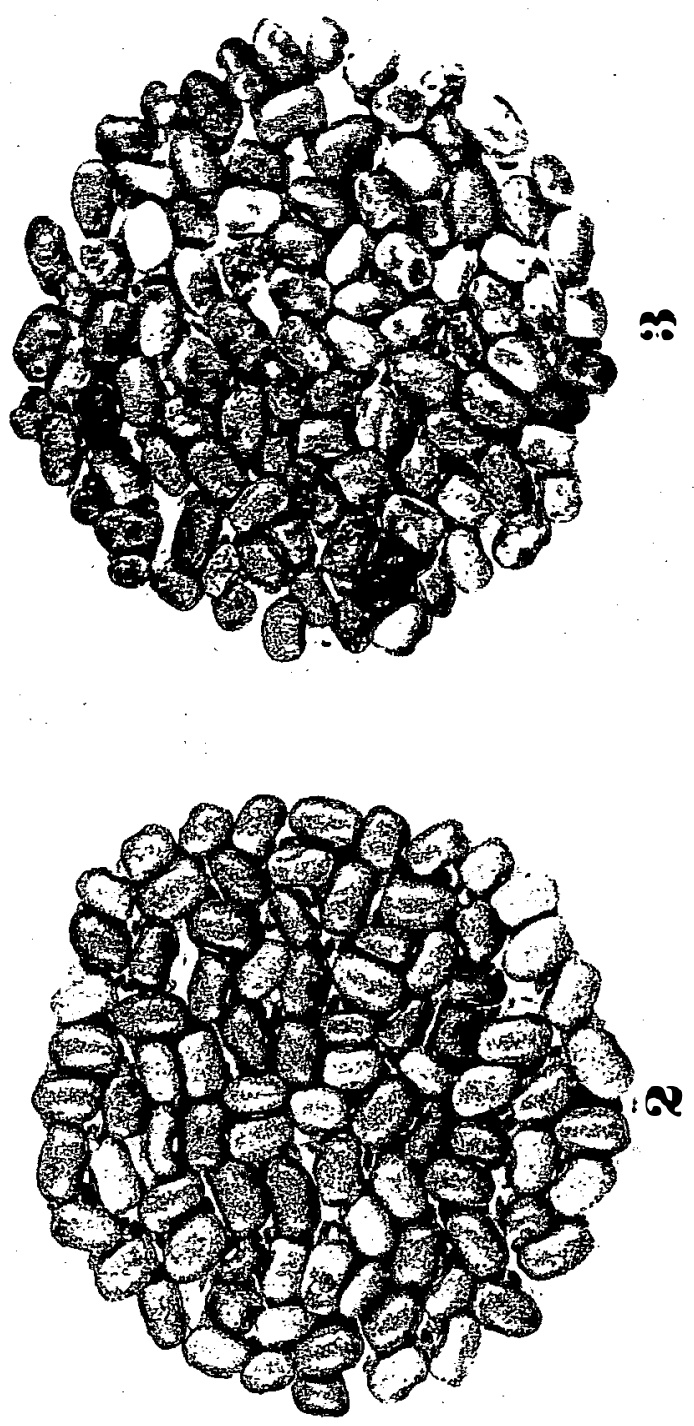

壱

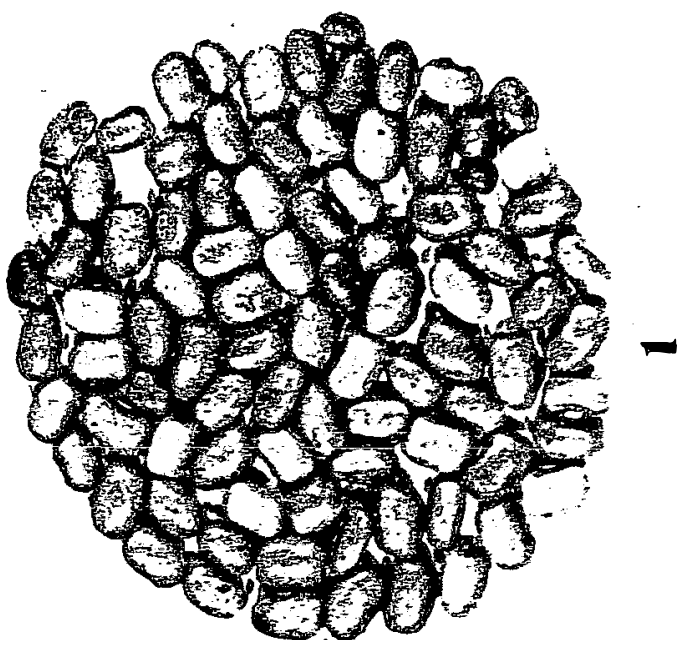


6. DISCUSSÃO

Estudos recentes, realizados por CUNHA e OLIVEIRA (1978), mostraram que a catação eletrônica pela cor, através da selecionadora eletrônica, promoveu o aumento da produção de lotes de sementes de feijão. Estes resultados, em parte, podem ser comparados aos obtidos no presente trabalho, embora neste, 0 teste de campo consistiu no registro de plantas emergidas e sobreviventes.0s resultados destes testes não mostraram efeitos benéficos das sementes catadas eletronicamente quando comparadas com a testemunha, porém evidenciaram a qualidade inferior das sementes descartadas pela máquina, pois as mesmas apresentaram menor número de plantas emergi das e sobreviventes.

Os testes de germinação e primeira contagem de germi nação, tambēm não detectaram diferenças entre as sementes catadas 
eletronicamente e nem mostraram haver diferenças entre o número de catações. Isto quer dizer que, uma catação seria suficiente para fa zer a remoção dos contaminantes indesejāveis que estavam presentes juntamente com as boas sementes.

Os dados apresentados nos Quadros 18, 19, 20 e 21 mostraram que era muito pequena a quantidade de contaminantes que de preciam a qualidade dos lotes de sementes, evidenciando desta forma, a boa qualidade das sementes.

o teste de envelhecimento rāpido não revelou valores de F significativos, como se pode observar no Quadro 4. Esses resul tados permitem salientar que são necessārias maiores informações so bre o emprego desse teste, uma vez que nem mesmo o material descartado apresentou-se menos vigoroso do que os demais beneficiamentos, contrariando assim as informações obtidas nas demais determinações. Segundo ISSA et alii (1964), uma das formas de se conseguir produzir sementes livres de patógenos é através de casa de vegetação ou em zonas áridas, onde as condições climáticas são desfavoráveis ao desenvolvimento de doenças da cultura. Ainda afirmam que a semente sadia é fundamental para se garantir a lavoura $1 \underline{i}$ vre de doenças e também se obter maiores produções. Como se pode ob servar, a qualidade das sementes é um dos fatores mais importantes e responsāveis para o bom desempenho da cultura.

Já foi dito anteriormente que sementes manchadas geralmente são portadoras de doenças que não só depreciam a qualidade 
do produto colhido como também chegam a provocar reduções nas co1heitas. No presente estudo observou-se que, com exceção das sementes carunchadas, a selecionadora eletrônica mostrou ser eficiente na remoção de sementes com mancha de levedura, sementes com outras man chas e sementes enrugadas, muito embora se tenha verificado que, através da anālise visual das sementes, o número de catações não mos trou diferenças significativas, em virtude da pouca quantidade des ses materiais.

E bom lembrar que, na escolha do material a ser estu dado, tentou-se primeiramente trabalhar com o feijão cultivar Aroana, mas observou-se que a máquina não trabalhou eficientemente, em virtude da desuniformidade na coloração das sementes, então optou-se para a cultivar Rosinha G-2, jā que era bem mais uniforme. Após as sementes terem sido submetidas a catação eletrônica, verificou-se que a mesma fez a remoção de sementes manchadas, quebradas, sementes sem tegumento e tambēm sementes de outras cultivares, por exemplo, feijão com o tegumento de coloração preta. Estes resultados concordam com os obtidos por BOYD (1967).

Merece ainda ser destacado que este trabalho serve para orientar outros pesquisadores que venham a se interessar em es tudar a eficiência da selecionadora eletrônica, pois não é ainda possível se afirmar com precisão que a máquina resolve os problemas de remoção de sementes manchadas, mas pelo menos fica evidenciada a possibilidade de remoção das mesmas. 
Quanto ao tratamento fungicida, embora estatisticamente não tenha revelado valores significativos na maioria dos testes, pode-se observar que, de uma certa forma, as sementes tratadas apresentaram resultados superiores às não tratadas. Talvez a razão de não se ter verificado efeitos marcantes do tratamento fungicida tenha sido devido à boa qualidade das sementes, levando a crer que o tratamento fungicida seja dispensável quando se tratar de sementes de qualidade superior, concord́ando com as afirmações de CARVALHO e NAKAGAWA (1980). 
7. CONCLUSÕES

Com base nos resultados obtidos no presente trabalho, pode-se concluir que:

a) a seleção eletrônica pela cor indica a possibilidade de se fazer a seperação de sementes portadoras de manchas sobre o tegumen to;

b) não houve efeito do número de catações sobre a qualidade das sementes;

c) as sementes descartadas pela máquina foram sempre de qualidade inferior;

d) houve efeito benéfico do tratamento fungicida apenas na pri meira contagem de germinação e na sobrevivência das plantas. 
55.

8. SUMMARY

Researches who had worked with beans, go solid against the bad quality of seeds by agriculture workers, as one of the most accountable for the low productivity of bean crop in Brazil.

Due to such situation, the present research has as its purpose to study the effect of color electronic separtion and chemical treatment on seed quality.

In this present research, seeds of beans (Phaseolus vulgaris L.) were utilized, to cultivate Rosinha G-2, coming from Agricultural Institute of Campinas, State of S. Paulo. The seeds after beeing benefited thru a machine air and screens, were. submitted to five electronic separation, by a national electronic separator "SELECTRON" - SM - 500, belonging to Agriculture and Horticul- 
ture Department of Escola Superior de Agricultura "Luiz de Queiroz", University of S. Paulo (D.A.H./ESALQ/USP), furthermore both the seeds electronically separated and the seeds not separated were treated with fungicide in order to verify its effects.

The effects of electronic separation, as well as of the chemical treatment of seeds were avaliated through germination tests, first germination score, accelereted aging, plantule emergen cy percentage, plantule survival, further it was done a visual and pathologic analysis of materials both electronically and of those non separated, separating unbleached seeds, seeds with yeast bleaches, wrinkled seeds, maggoty seeds and seeds with microorganisms.

With the analysis and interpretation of the results we can draw the conclusion that: the electronic separator was able to separate the bleached seeds from the unbleached ones; there was no effect of the number of separation upon the seed quality; the seeds thrown away by the machine were always of inferior quality; there was a benefic effect of chemical treatment on the first score of plant germination and survival. 
57.

9. LITERATURA CITADA

BASTOS CRUZ, B.P., 1962. Feijão com antracnose. O Biológico, 28: 118.

BOYD Jr., A.H., 1967. Potencial applications of eletric color sorting techniques in seed technology. Mississipi State University. State College, Mississipi. 60 p. (Tese de M.S.).

BRASIL. Fundação Instituto Brasileiro de Geografia e Estatística, 1977. Anuārio Estatístico. Rio de Janeiro, 28: 1-848.

BRASIL. MINISTERIO DA AGRICULTURA, 1976. Regras para Anālise de Se-mentes. Departamento Nacional de Produção Vegetal (DNPV).. Divisão de Sementes e Mudas (DISEM). $188 \mathrm{p}$.

BYRD, H.W. e J.C. DELOUCHE, 1971. Deterioration of soybean seed in storage. Proc. Ass. Off. Seed Anal., 61: 41-57. 